\title{
A Shear-Mode Piezoelectric Heterostructure for Electric Current Sensing in Electric Power Grids
}

\author{
Wei $\mathrm{He}^{1, *(1)}$ and Aichao Yang ${ }^{2}$ \\ 1 School of Information Engineering, Baise University, Baise 533000, China \\ 2 Jiangxi Electric Power Research Institute, Nanchang 330096, China; dkyyac2015@163.com \\ * Correspondence: weiheky@yeah.net
}

Received: 1 June 2019; Accepted: 21 June 2019; Published: 23 June 2019

check for updates

\begin{abstract}
This paper presents a shear-mode piezoelectric current sensing device for two-wire power cords in electric power grids. The piezoelectric heterostructure consists of a cymbal structure and a permalloy plate. The cymbal structure is constructed from a permanent magnet, a brass cap, and shear-mode piezoelectric materials. The permalloy plate concentrates the magnetic field generated by the two-wire power cord on the magnet. Under the force amplification effect of the cymbal structure, the response of the device is improved. A prototype has been fabricated to conduct the experiments. The experimental average sensitivity of the device is $12.74 \mathrm{mV} / \mathrm{A}$ in the current range of 1-10 A with a separating distance of $\mathrm{d}=0 \mathrm{~mm}$, and the resolution reaches $0.04 \mathrm{~A}$. The accuracy is calculated to be $\pm 0.0177 \mathrm{mV}$ at $1.5 \mathrm{~A}$ according to the experimental voltage distribution. The current-to-voltage results demonstrate that the proposed heterostructure can also be used as a magnetoelectric device without bias.
\end{abstract}

Keywords: piezoelectric current sensing device; two-wire power cord; cymbal structure; force amplification effect; sensitivity

\section{Introduction}

Electricity monitoring of power lines based on current sensing devices is of great significance to improve the security and reliability of the electric power systems. The traditional current sensing devices, such as Hall sensors [1], magnetoresistance sensors [2,3], and current transformers [4], have been investigated. But there are some limitations for these devices. The Hall sensors require external power and place high demands on signal conditioners due to the weak Hall voltage. Magnetoresistance sensors also need external power supply and exhibit large thermal drifts. Current transformers have the disadvantage of magnetic saturation and relay maloperation might be induced. Magnetoelectric (ME) structures based on magnetostrictive materials and piezoelectric materials have been reported for current measuring [5-8], but the devices need to encircle the wire in operation, which may limit their real applications. Furthermore, most of the previously proposed ME structures require DC bias magnetic field, and the demand for DC bias magnetic field greatly increases the occupied space. Cantilever-based non-invasive piezoelectric current sensors are proposed [9-11]. The devices are designed to resonate at the power frequency $(50 \mathrm{~Hz}$ or $60 \mathrm{~Hz})$ to obtain maximal responses. However, due to the nonlinearity of the piezoelectric materials [12], it is difficult to maintain the resonant state of the devices for varying current amplitudes, and non-resonant structures are more suitable for current sensing. Recently, non-resonant piezoelectric current sensing devices were developed for a single wire in electric power grids [13,14], which operate non-invasively and exhibit high linearity, but the proposed structures are not suited for a two-wire power cord carrying identical currents in opposite directions.

In the past several years, the shear effect of the piezoelectric materials has attracted great attention due to the high piezoelectric constant and electromechanical coupling coefficient [15-21]. Ren et al. [15] presented a shear-mode piezoelectric vibration energy harvesting device with a maximum 
output power of $4.16 \mathrm{~mW}$. Carrera et al. [16,17] analyzed multilayered piezoelectric structures in shear-mode using finite element models (e.g., LW models with different theory approximation orders). Liu et al. [21] theoretically investigated the ME effect of a magnetoelectric laminated composite working in shear-shear (S-S) mode, which exhibits stronger ME coupling coefficients. In this paper, a shear-mode non-resonant piezoelectric heterostructure for current sensing of two-wire power cords is designed. The brass cap, the shear-mode piezoelectric materials, and the permanent magnet constitute a cymbal structure, which results in force amplification and potential enhancement of the response to the currents. Theoretical study was conducted, and a prototype was fabricated to investigate the output characteristics of the device. The least squares method is used to analyze the linearity, and the accuracy is investigated for a given electric current. The prototype exhibits high linearity and sensitivity, which are favorable for current sensing in electric power grids. The experimental results verify the theoretical model and the feasibility of the proposed heterostructure. Meanwhile, a conversion factor of $0.77 \mathrm{~V} / \mathrm{A}$ is obtained for the current-to-voltage conversion experiment, which indicates the latent advantages of the proposed device in practical applications compared with the magnetoelectric laminated composites using DC bias magnetic field [21-24].

\section{Structure and Analysis}

Figure 1 shows the schematic diagram and photograph of the proposed piezoelectric heterostructure. The device comprises a cymbal structure and a permalloy plate. The cymbal structure is constructed from a magnet, two shear-mode piezoelectric plates, and a brass cap. The piezoelectric ceramic $\mathrm{Pb}(\mathrm{Zr}, \mathrm{Ti}) \mathrm{O}_{3}(\mathrm{PZT} 5 \mathrm{H})$ is chosen as the material of the piezoelectric plates. The dimension of each PZT5H plate is $1 \mathrm{~mm}\left(d_{p}\right) \times 6 \mathrm{~mm}\left(w_{p}\right) \times 3 \mathrm{~mm}\left(l_{p}\right)$. The material of the permanent magnet is $\mathrm{NdFeB}(\mathrm{N} 35)$, and the size of the magnet is $5 \mathrm{~mm}\left(d_{m}\right) \times 6 \mathrm{~mm}\left(w_{m}\right) \times 22 \mathrm{~mm}\left(l_{m}\right)$. The magnet also acts as a retaining plate for the cymbal structure. Under the action of the AC magnetic field produced by the two-wire power cord, the magnet is acted upon by an AC magnetic force due to the nonuniform AC magnetic field acting on the magnet. The magnetic force results in amplified shear stress on the piezoelectric plates. Then, a voltage is produced, due to the piezoelectric effect of the piezoelectric material.

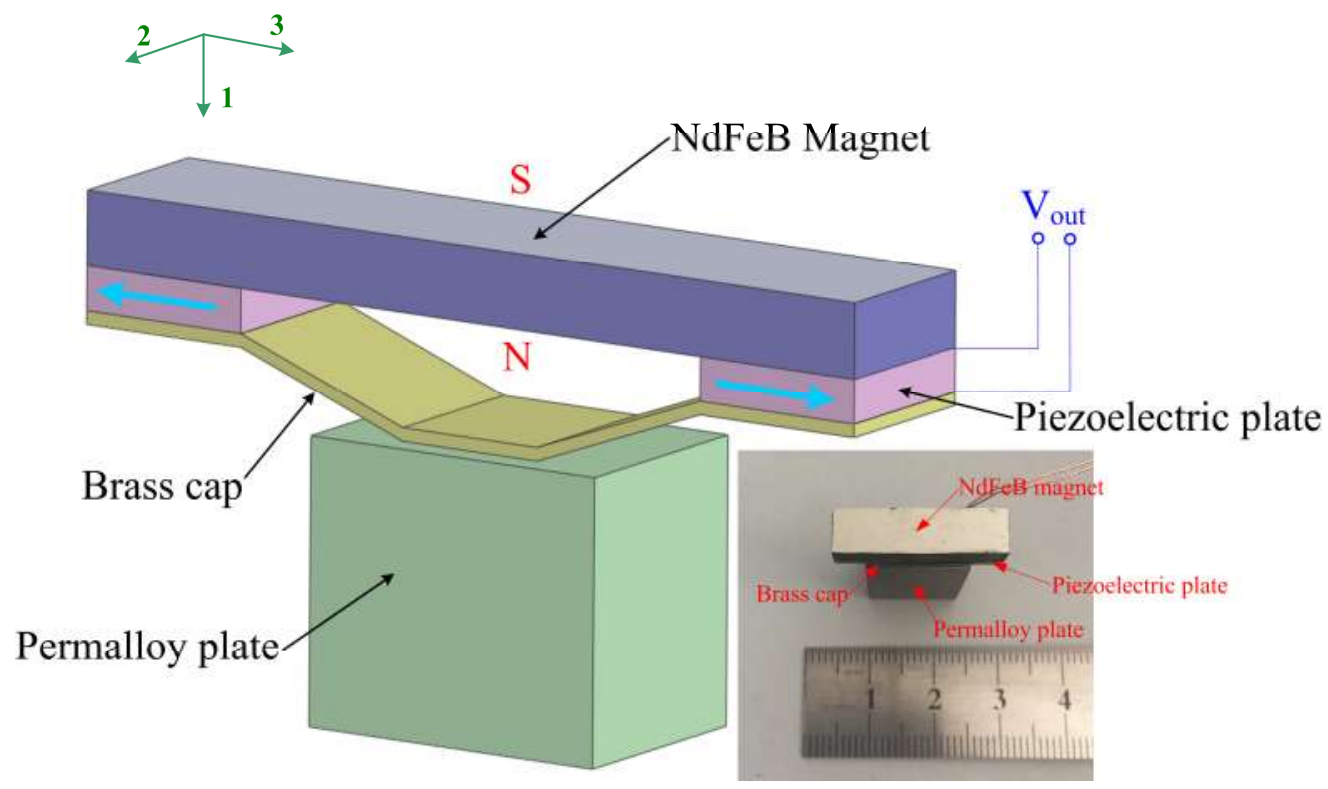

Figure 1. Schematic diagram and photograph of the proposed piezoelectric heterostructure. 
The magnetic force on the magnet $F_{m}$ can be expressed as

$$
\begin{gathered}
F_{m}=\sigma_{m} \iint_{S_{m}} \Delta H d S_{m}, \\
\Delta H=H_{1 a}-H_{1 b},
\end{gathered}
$$

where $\sigma_{m}$ is the magnetic charge density, $\sigma_{m}=B_{r}$ [25], $B_{r}$ is the remnant flux density, $S_{m}$ is the surface area of one pole of the magnet, and $H_{1 a}$ and $H_{1 b}$ are the magnetic fields on the bottom and top surfaces of the magnet, respectively. $F_{m}$ can be expressed as a power series of the electric current $I$, and the coefficients of the power series can be determined by fitting curve. Assuming that the vertical force (in 1-direction) acting on one piezoelectric plate by the magnet is $F_{m} / 2$, the vertical force acting on the magnet by one piezoelectric plate is the same in amplitude and opposite in direction $\left(-F_{m} / 2\right)$.

Figure 2 shows the force $F_{t}$ exerted by the brass cap on one piezoelectric plate. Based on the decomposition of the force $F_{t}$, the following equation is obtained

$$
F_{v}=-\frac{F_{m}}{2}
$$

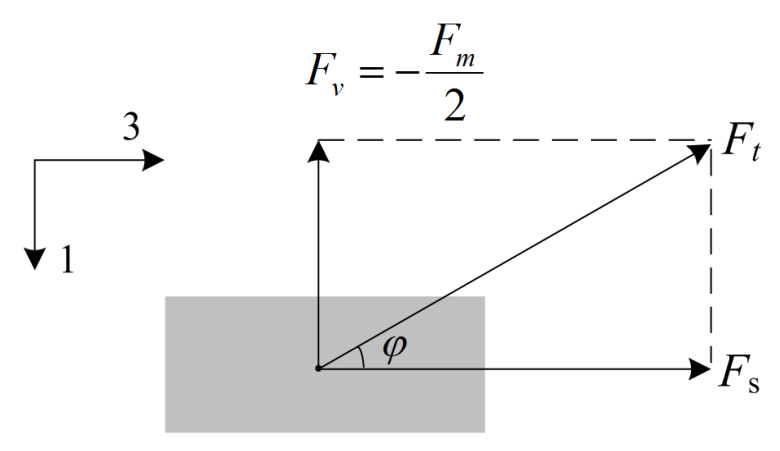

Figure 2. The force $F_{t}$ exerted by the brass cap on a piezoelectric plate.

The shear force $F_{S}$ (in 3-direction) can be expressed as

$$
F_{s}=-\frac{F_{v}}{\operatorname{tg} \varphi}
$$

where $\operatorname{tg} \varphi$ is determined by

$$
\operatorname{tg} \varphi=\frac{2\left(h-d_{p}\right)}{l_{m}-2 l_{p}-l_{t}}
$$

where $h$ is the distance between the magnet ( $\mathrm{N}$ pole) and the top part (inner surface) of the brass cap, $d_{p}$ and $l_{p}$ are respectively the thickness (in 1-direction) and length (in 3-direction) of one piezoelectric plate, $l_{m}$ is the length of the magnet $\left(w_{m}\right.$ and $d_{m}$ are respectively the width and the thickness of the magnet), and $l_{t}$ is the length of the top part of the brass cap. Then, the shear stress acting on one piezoelectric plate is

$$
T_{s}=\frac{F_{s}}{w_{p} l_{p}}=-\frac{F_{v}}{w_{p} l_{p} t g \varphi},
$$

where $w_{p}$ is the width of one piezoelectric plate. Based on piezoelectric constitutive equations in shear-mode [26], the electric field in 1-direction of the piezoelectric material is given by

$$
E_{1}=-h_{15} S_{5}=h_{15} \frac{F_{v}}{w_{p} l_{p} \operatorname{tg} \varphi c_{55}^{D}}
$$


where $h_{15}$ is the shear stiffness constant, and $c_{55}^{D}$ is the elastic stiffness coefficient (at constant $D_{1}$ ) in shear-mode. In open-circuit condition, the electric displacement $D_{1}=0$. Thus, the output voltage of one piezoelectric plate is obtained as

$$
V_{1}=E_{1} d_{p}=-\frac{F_{m} h_{15} d_{p}}{2 w_{p} l_{p} \operatorname{tg} \varphi c_{55}^{D}}
$$

Based on Equation (8), it is obvious that the voltage is proportional to the magnetic force $F_{m}$ for determined material and geometric parameters of the device, which depends on the magnetic field magnetic field gradient $\Delta H$ on the $\mathrm{NdFeB}$ magnet. For current-to-voltage conversion application, the conversion factor can be defined as

$$
\gamma=\frac{V_{1}}{I_{c o i l}}=-\frac{F_{m} h_{15} d_{p}}{2 w_{p} l_{p} I_{c o i l} \operatorname{tg} \varphi c_{55}^{D}}
$$

If the output voltage exhibits a linear response to the input current of the coil, the conversion factor $\lambda$ will show a flat response to the current.

\section{Results and Discussions}

A prototype was fabricated to study the current sensing performances of the device. The fabrication process is as follows. (1) The brass cap, the piezoelectric plates (PZT5H), the permalloy plate, and the permanent magnet $(\mathrm{NdFeB})$ were dipped in propanone to clean. (2) The brass cap, the piezoelectric plates, and the $\mathrm{NdFeB}$ magnet were bonded to constitute the cymbal structure using insulate epoxy adhesive, and the cymbal structure was naturally dried in the air. (3) The permalloy plate was bonded with the cymbal structure. The prototype was then used to current sensing for a two-wire power cord. The configuration and the experimental set-up for the presented device are illustrated in Figure 3 (the power cord carries opposite currents). The electric currents of the two-wire power cord were generated by a current generator, and the output voltages were monitored by a lock-in amplifier. The current sensing device was placed above the two-wire power cord. The permalloy plate concentrates the magnetic field produced by the two wires of the power cord to the NdFeB magnet, which can potentially enhance the response of the device to electric currents. In Figure 3, the parameter $d$ represents the distance between the bottom surface of the permalloy plate and the top surface of the power cord.

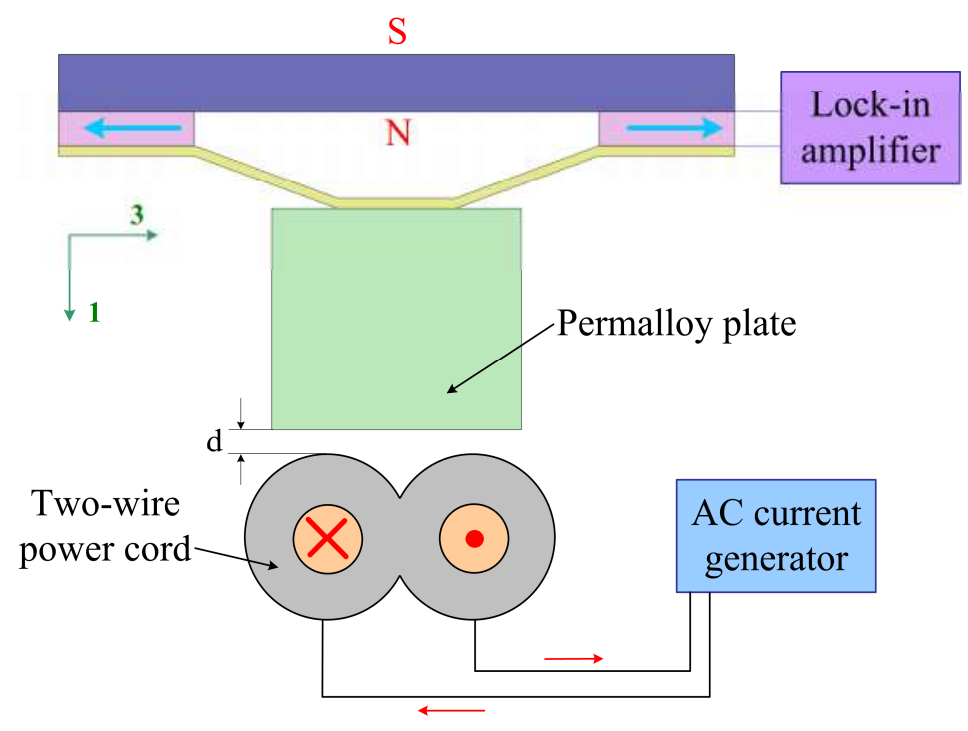

Figure 3. Configuration and experimental set-up for the proposed device. 
Figure 4 shows the output peak voltage versus the current in the power cord $(f=50 \mathrm{~Hz})$. It can be seen from Figure 4 that the experimental voltage increases from $13.91 \mathrm{mV}$ to $128.59 \mathrm{mV}$ when the current is increased from $1 \mathrm{~A}$ to $10 \mathrm{~A}$ for $d=0 \mathrm{~mm}$, and the average sensitivity is $12.74 \mathrm{mV} / \mathrm{A}$ in the given current range (1-10 A). For $d=3 \mathrm{~mm}$, there is an obvious drop for the induced voltages, and the voltage varies from $7.23 \mathrm{mV}$ to $59.48 \mathrm{mV}$ with an average sensitivity of $5.81 \mathrm{mV} / \mathrm{A}$. The theoretical voltages obtained from Equation (8) for $4 \mathrm{~A}, 6 \mathrm{~A}$, and $8 \mathrm{~A}$ at $d=0 \mathrm{~mm}$ were plotted in Figure 4 (respectively $60.5 \mathrm{mV}, 88.1 \mathrm{mV}$, and $114.2 \mathrm{mV}$ ), which validate the developed model. In order to analyze the linearity of the proposed device, the least squares method was adopted. The equation of the fitting curve can be expressed as

$$
V=a I+b,
$$

where $a$ is the slope and $b$ is the intercept of the equation. Using the experimental data in Figure 4, the slope of the equation $a=12.82077$ for $d=0 \mathrm{~mm}$ and $a=5.785861$ for $d=3 \mathrm{~mm}$. Correspondingly, the intercept $b=1.546273$ for $d=0 \mathrm{~mm}$ and $b=1.548193$ for $d=3 \mathrm{~mm}$. The correlation coefficients are 0.999897 and 0.999945 for $d=0 \mathrm{~mm}$ and $d=3 \mathrm{~mm}$, respectively. After plotting the fitting curves in Figure 4, the linearity of the proposed device is calculated by

$$
\delta=\frac{\Delta V_{\max }}{V_{\max }} \times 100 \%,
$$

where $\Delta V_{\max }$ is maximal deviation between the experimental results and the fitting results, and $V_{\max }$ represents the full-scale output of the device. The corresponding results are $0.9 \%$ and $0.67 \%$ for $d=$ $0 \mathrm{~mm}$ and $d=3 \mathrm{~mm}$, respectively. Compared with the resonant structures, the high linearity makes the presented device very suitable for current sensing in electric power systems.

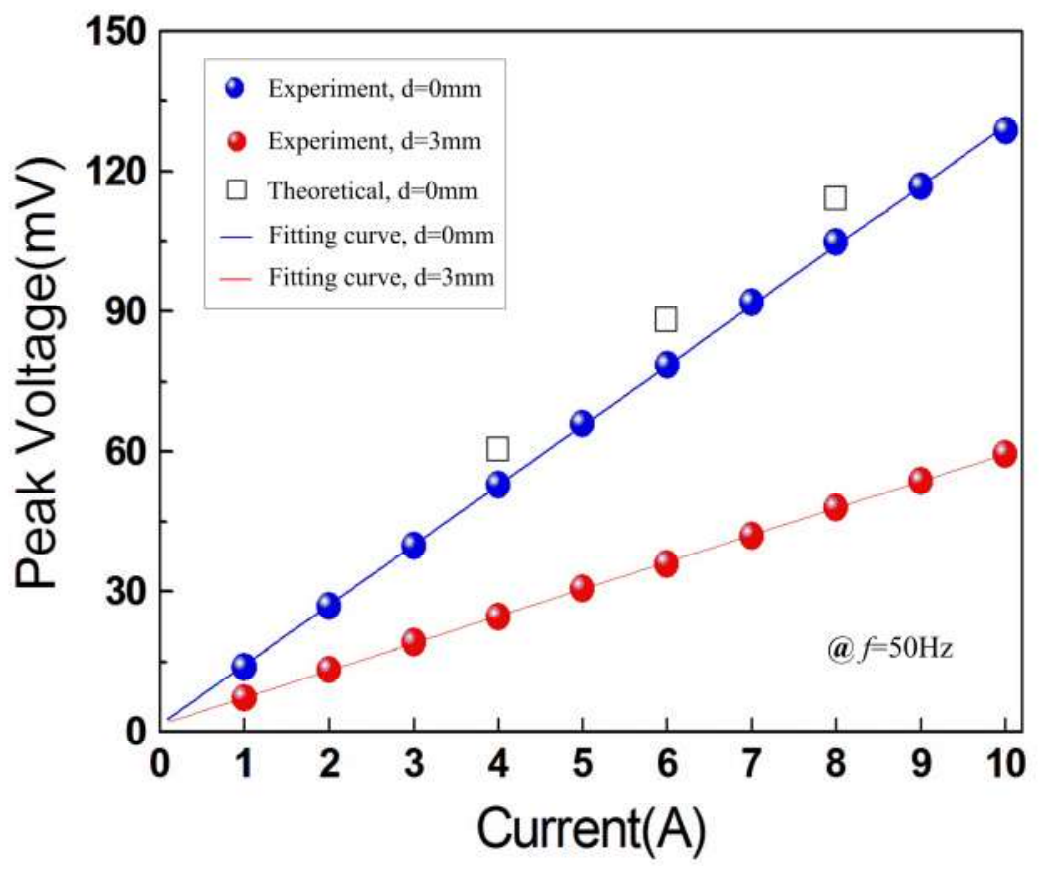

Figure 4. Induced voltage versus the electric current for $d=0 \mathrm{~mm}$ and $d=3 \mathrm{~mm}$.

The current remains unchanged at $1.5 \mathrm{~A}(f=50 \mathrm{~Hz})$. Figure 5a plots the induced experimental voltage at different times. As can be seen from Figure $5 \mathrm{a}$, the voltage changes with time. The average voltage is $20.4 \mathrm{~mA}$ (measurement number $n=120$ ) in the given time range $(0-1200 \mathrm{~s})$. The histogram of the voltages is shown in Figure $5 b$. It can be seen from Figure $5 b$ that the voltages approximately obey normal distribution. Therefore, the accuracy of the device for current sensing can be calculated by 


$$
A=v \pm \frac{4 \sigma}{\sqrt{n}},
$$

where $v$ is the systematic error, $\sigma$ is the standard deviation, and $\pm 4 \sigma / \sqrt{n}$ represents the uncertainty. If we do not take into account the systematic error, the accuracy of the device is calculated to be $\pm 0.0177 \mathrm{mV}$.
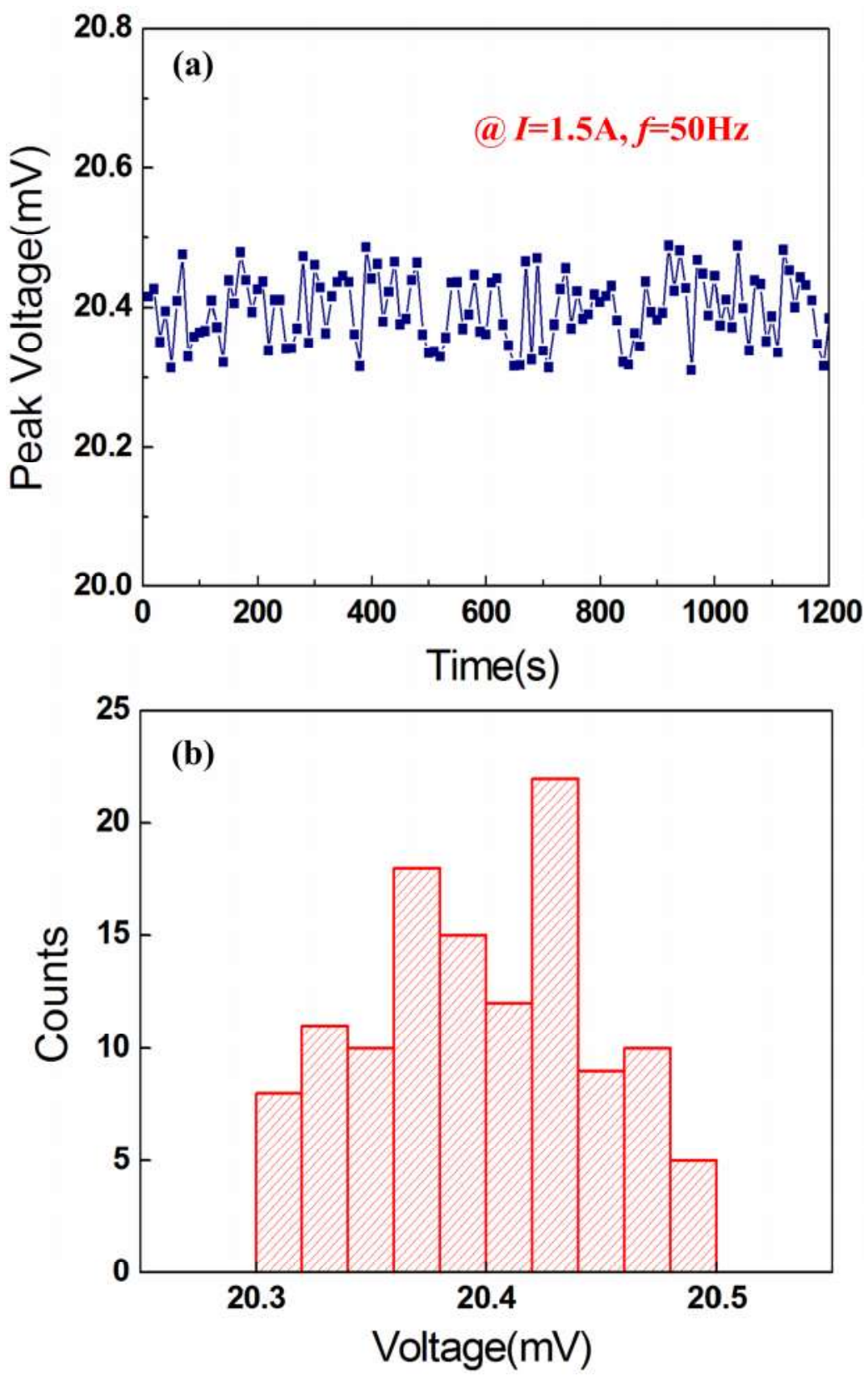

Figure 5. (a) Induced voltage versus time at $50 \mathrm{~Hz}$ for $d=0 \mathrm{~mm}$ and (b) Histogram for the voltage at $1.5 \mathrm{~A}$.

A small current step $(\Delta I=0.04 \mathrm{~A}, f=50 \mathrm{~Hz})$ was applied in the two-wire power cord. Figure 6 shows the induced experimental voltage versus time for $d=0 \mathrm{~mm}$. As can be seen from Figure 6 , by adjusting the current amplitudes within $140 \mathrm{~s}$, the output voltage exhibits a step change. It is clear that a current change $(\Delta I)$ of $0.04 \mathrm{~A}$ can be distinguished. We predict further resolution improvement could be achieved by replacing the PZT5H with shear-mode PMN-PT single crystal, which has a higher piezoelectric coefficient $d_{15}$. 


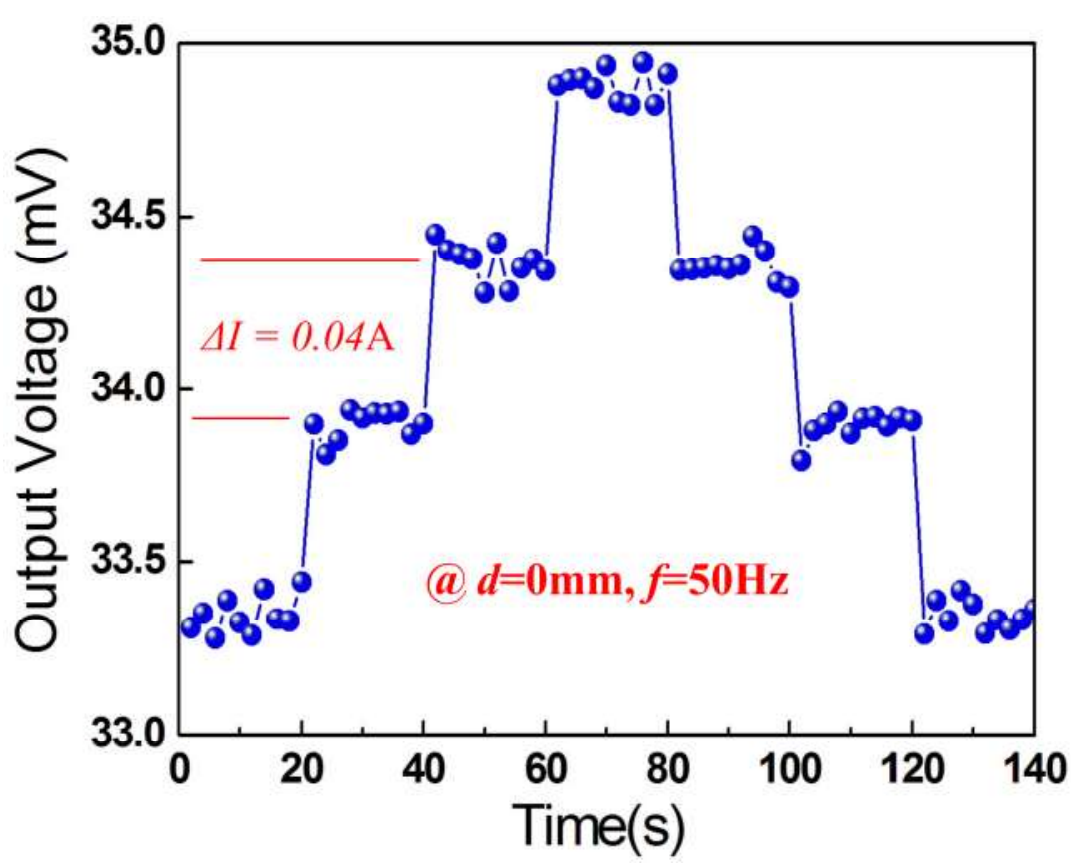

Figure 6. Resolution of the device to the power-frequency current step of $0.04 \mathrm{~A}$ at $d=0 \mathrm{~mm}$.

A copper wire coil was wound around the permalloy plate of the prototype, and a current of $40 \mathrm{~mA}-400 \mathrm{~mA}\left(I_{\mathrm{in}}\right)$ was applied in the coil for current-to-voltage conversion. The experimental output peak voltage increases from $33.18 \mathrm{mV}$ to $270.85 \mathrm{mV}$ with approximately linear response to the current at the low-frequency of $1 \mathrm{kHz}$, as shown in Figure 7 . It also can be seen from the inset of Figure 7 that the factor $\lambda$ exhibits an approximate flat response. It varies in the range of $0.68 \mathrm{~V} / \mathrm{A}$ to $0.83 \mathrm{~V} / \mathrm{A}$, with an average value of $0.77 \mathrm{~V} / \mathrm{A}$. The results show that the heterostructure has the potential to produce large magnetoelectric effect without using magnetostrictive materials and bias magnetic field [27,28].

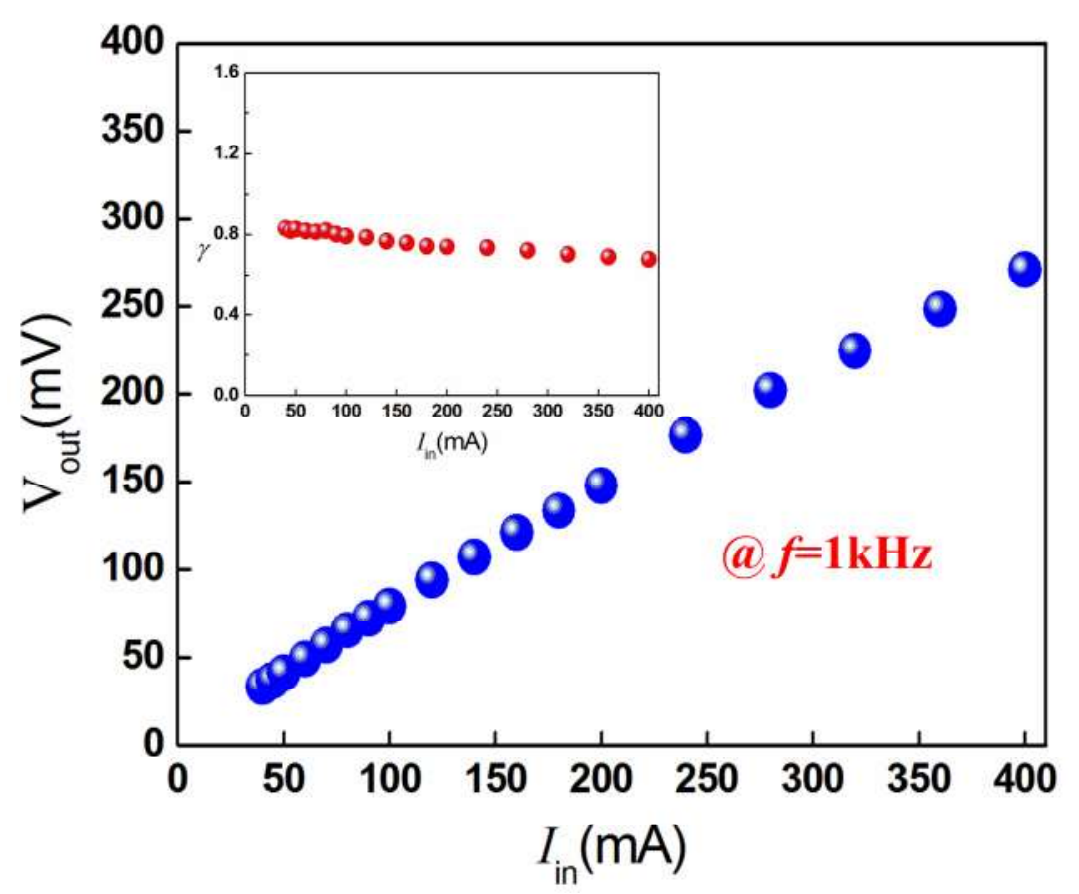

Figure 7. Output open-circuit voltage as a function of the input electric current in the coil at $1 \mathrm{kHz}$. The inset indicates the conversion factor in the current range of $40 \mathrm{~mA}$ to $400 \mathrm{~mA}$. 


\section{Conclusions}

In this paper, a non-resonant piezoelectric current sensing device with high resolution is proposed, which possesses the advantages of passivity, low cost, and simple structure. The device can operate non-invasively for a two-wire power cord carrying opposite currents. The sensitivity of the structure is improved due to the force amplification effect of the cymbal structure and the concentration effect of the permalloy plate. A theoretical model has been developed and validated by the experiments. A large current sensitivity of $12.74 \mathrm{mV} / \mathrm{A}(d=0 \mathrm{~mm})$ and a high linearity of $0.67 \%(d=3 \mathrm{~mm})$ are obtained. The experimental current-to-voltage results demonstrate the potential of a large magnetoelectric effect of the proposed piezoelectric device at low-frequency applications.

Author Contributions: W.H. performed the analysis and the experiments; A.Y analyzed the experimental results; W.H. wrote the paper; all authors reviewed the manuscript.

Funding: This work is supported by the National Natural Science Foundation of China (Grant Nos. 61761001 and 61540039) and the Natural Science Foundation of Guangxi Province (Grant No. 2015GXNSFBA139263).

Conflicts of Interest: The authors declare no conflicts of interest.

\section{References}

1. Cataliotti, A.; Di Cara, D.; Emanuel, A.E.; Nuccio, S. Improvement of Hall effect current transducer metrological performances in the presence of harmonic distortion. IEEE Trans. Instrum. Meas. 2010, 59, 1091-1097. [CrossRef]

2. Mlejnek, P.; Vopálenský, M.; Ripka, P. AMR current measurement device. Sens. Actuators A 2008, 141, 649-653. [CrossRef]

3. Jedlicska, I.; Weiss, R.; Weigel, R. Linearizing the output characteristic of GMR current sensors through hysteresis modeling. IEEE Trans. Ind. Electron. 2009, 57, 1728-1734. [CrossRef]

4. Salach, J.; Hasse, L.; Szewczyk, R.; Smulko, J.; Bienkowski, A.; Frydrych, P.; Kolano-Burian, A. Low current transformer utilizing Co-based amorphous alloys. IEEE Trans. Magn. 2012, 48, 1493-1496. [CrossRef]

5. Dong, S.; Li, J.F.; Viehland, D. Circumferentially magnetized and circumferentially polarized magnetostrictive/piezoelectric laminated rings. J. Appl. Phys. 2004, 96, 3382-3387. [CrossRef]

6. Leung, C.M.; Or, S.W.; Zhang, S.; Ho, S.L. Ring-type electric current sensor based on ring-shaped magnetoelectric laminate of epoxy-bonded $\mathrm{Tb}_{0.3} \mathrm{Dy}_{0.7} \mathrm{Fe}_{1.92}$ short-fiber/NdFeB magnet magnetostrictive composite and $\mathrm{Pb}(\mathrm{Zr}, \mathrm{Ti}) \mathrm{O}_{3}$ piezoelectric ceramic. J. Appl. Phys. 2010, 107, 09D918.

7. Zhang, J.; Li, P.; Wen, Y.; He, W.; Yang, A.; Lu, C.; Qiu, J.; Wen, J.; Yang, J.; Zhu, Y.; et al. High-resolution current sensor utilizing nanocrystalline alloy and magnetoelectric laminate composite. Rev. Sci. Instrum. 2012, 83, 115001. [CrossRef]

8. Zhang, J.; He, W.; Zhang, M.; Zhao, H.; Yang, Q.; Guo, S.; Wang, X.; Zheng, X.; Cao, L. Broadband high-sensitivity current-sensing device utilizing nonlinear magnetoelectric medium and nanocrystalline flux concentrator. Rev. Sci. Instrum. 2015, 86, 095005. [CrossRef]

9. Leland, E.S.; Wright, P.K.; White, R.M. Design of a MEMS passive, proximity-based AC electric current sensor for residential and commercial loads. Proc. PowerMEMS 2007, 77-80.

10. Leland, E.S.; Wright, P.K.; White, R.M. A MEMS AC current sensor for residential and commercial electricity end-use monitoring. J. Micromech. Microeng. 2009, 19, 094018. [CrossRef]

11. Lu, C.; Li, P.; Wen, Y.; Yang, A.; Yang, C.; Wang, D.; He, W.; Zhang, J. Zero-biased magnetoelectric composite $\mathrm{Fe}_{73.5} \mathrm{Cu}_{1} \mathrm{Nb}_{3} \mathrm{Si}_{13.5} \mathrm{~B}_{9} / \mathrm{Ni} / \mathrm{Pb}\left(\mathrm{Zr}_{1-\mathrm{x}}, \mathrm{Ti}_{\mathrm{x}}\right) \mathrm{O}_{3}$ for current sensing. J. Alloys Compd. 2014, 589, 498-501.

12. Shen, D.; Park, J.H.; Noh, J.H.; Choe, S.Y.; Kim, S.H.; Wikle, H.C., III; Kim, D.J. Micromachined PZT cantilever based on SOI structure for low frequency vibration energy harvesting. Sens. Actuators A 2009, 154, $103-108$.

13. He, W.; Li, P.; Wen, Y.; Zhang, J.; Yang, A.; Lu, C. Note: A high-sensitivity current sensor based on piezoelectric ceramic $\mathrm{Pb}(\mathrm{Zr}, \mathrm{Ti}) \mathrm{O}_{3}$ and ferromagnetic materials. Rev. Sci. Instrum. 2014, 85, 026110. [CrossRef]

14. He, W.; Lu, Y.; Qu, C.; Peng, J. A non-invasive electric current sensor employing a modified shear-mode cymbal transducer. Sens. Actuators A 2016, 241, 120-123. [CrossRef] 
15. Ren, B.; Or, S.W.; Zhang, Y.; Zhang, Q.; Li, X.; Jiao, J.; Wang, W.; Liu, D.; Zhao, X.; Luo, H. Piezoelectric energy harvesting using shear mode $0.71 \mathrm{~Pb}\left(\mathrm{Mg}_{1 / 3} \mathrm{Nb}_{2 / 3}\right) \mathrm{O}_{3}-0.29 \mathrm{PbTiO}_{3}$ single crystal cantilever. Appl. Phys. Lett. 2010, 96, 083502.

16. Carrera, E.; Valvano, S.; Kulikov, G.M. Multilayered plate elements with node-dependent kinematics for electro-mechanical problems. Int. J. Smart Nano Mater. 2018, 9, 279-317. [CrossRef]

17. Carrera, E.; Valvano, S.; Kulikov, G.M. Electro-mechanical analysis of composite and sandwich multilayered structures by shell elements with node-dependent kinematics. Int. J. Smart Nano Mater. 2018, 9, 1-33. [CrossRef]

18. Zhu, Y.; Zheng, X.; Li, L.; Yu, Y.; Liu, X.; Chen, J. Evaluation of shear piezoelectric coefficient $\mathrm{d}_{15}$ of piezoelectric ceramics by using piezoelectric cantilever beam in dynamic resonance. Ferroelectrics 2017, 520, 202-211. [CrossRef]

19. Gao, X.; Xin, X.; Wu, J.; Chu, Z.; Dong, S. A multilayered-cylindrical piezoelectric shear actuator operating in shear $\left(\mathrm{d}_{15}\right)$ mode. Appl. Phys. Lett. 2018, 112, 152902. [CrossRef]

20. Qin, L.; Jia, J.; Choi, M.; Uchino, K. Improvement of electromechanical coupling coefficient in shear-mode of piezoelectric ceramics. Ceram. Int. 2019, 45, 1496-1502. [CrossRef]

21. Liu, G.; Zhang, C.; Dong, S. Magnetoelectric effect in magnetostrictive/piezoelectric laminated composite operating in shear-shear mode. J. Appl. Phys. 2014, 116, 074104. [CrossRef]

22. Zhai, J.; Xing, Z.; Dong, S.; Li, J.; Viehland, D. Magnetoelectric laminate composites: an overview. J. Am. Ceram. Soc. 2008, 91, 351-358. [CrossRef]

23. Yao, Y.P.; Hou, Y.; Dong, S.N.; Li, X.G. Giant magnetodielectric effect in Terfenol-D/PZT magnetoelectric laminate composite. J. Appl. Phys. 2011, 110, 014508. [CrossRef]

24. Liu, Y.; Xu, G.; Xie, Y.; Lv, H.; Huang, C.; Chen, Y.; Tong, Z.; Shi, J.; Xiong, R. Magnetoelectric behaviors in $\mathrm{BaTiO}_{3} / \mathrm{CoFe}_{2} \mathrm{O}_{4} / \mathrm{BaTiO}_{3}$ laminated ceramic composites prepared by spark plasma sintering. Ceram. Int. 2018, 44, 9649-9655. [CrossRef]

25. Xu, Y.; Jiang, Z.S.; Wang, Q.; Xu, X.; Sun, D.S.; Zhou, J.; Yang, G. Three dimensional magnetostatic field calculation using equivalent magnetic charge method. IEEE Trans. Magn. 1991, 27, 5010-5012. [CrossRef]

26. Ikeda, T. Fundamentals of Piezoelectricity; Oxford University Press: Oxford, UK, 1990; pp. 38-39.

27. Zeng, M.; Or, S.W.; Chan, H.L.W. Giant resonance frequency tunable magnetoelectric effect in a device of $\mathrm{Pb}\left(\mathrm{Zr}_{0.52} \mathrm{Ti}_{0.48}\right) \mathrm{O}_{3}$ drum transducer, NdFeB magnet, and Fe-core solenoid. Appl. Phys. Lett. 2010, 96, 203502.

28. Zeng, M.; Or, S.W.; Chan, H.L.W. Giant magnetoelectric effect in magnet-cymbal-solenoid current-to-voltage conversion device. J. Appl. Phys. 2010, 107, 074509. [CrossRef] 